dass nicht thematisiert wurde - möglicherweise fehlten zum damaligen Zeitpunkt noch gesicherte detaillierte Informationen -, dass auch die unteren Ränge der Partei, also auch die »einfachen« Parteimitglieder, gesäubert wurden. ${ }^{490}$ Zum anderen wurde von Löwenthal nicht ausdrücklich angesprochen, dass vom stalinistischen Terror nach dem Ende des Zweiten Weltkrieges Millionen sowjetischer Bürger aufgrund von Massen- und Bevölkerungsdeportationen betroffen waren und unter anderem Zwangsarbeit in den sowjetischen Lagern leisten mussten. Bei Löwenthal war ausschließlich davon die Rede, dass dem »russischen Volk« im Kontext der allgemeinen staatlichen Industriepolitik »schwere Opfer « auferlegt wurden. ${ }^{491}$

\title{
2.6 Der Nachstalinismus: das kommunistische Herrschaftssystem unter Chruschtschow
}

Nach dem für die Weltöffentlichkeit überraschenden Tod von Stalin am 5. März 1953 setzte in der Zeitschrift Der Monat sofort eine Diskussion ein, die sowohl politische als auch theoretische Aspekte beinhaltete und die vor allem im Kern die analytisch ausgerichtete Frage fokussierte, welche Bedeutung das Ableben des unumstrittenen Parteiführers für das sowjetkommunistische Herrschaftssystem haben könnte. Das hieß in diesem Zusammenhang auch, dass seitens verschiedener Autoren die Frage thematisiert wurde, welche innen- und außenpolitische Entwicklung die Sowjetunion nehmen könnte. Es ging also hierbei auch um die sich besonders angesichts des Kalten Krieges aufdrängende Frage, welche grundsätzliche politische und gesellschaftliche Entwicklung das nachstalinistische System nehmen könnte, ob die Sowjetunion möglicherweise expansive außenpolitische Ziele verfolgen und insofern in den Augen der westlich-demokratischen Staaten eine unmittelbare militärische Bedrohung darstellen würde. Angesichts der zeitlichen Aktualität besaßen die Veröffentlichungen selbstverständlich einen hochspekulativen Charakter, ging es doch darum, ebendiese mögliche Veränderung der Sowjetunion nach Stalins Tod zu prognostizieren, also vorherzusagen. Denn es ging nicht zuletzt auch um die Frage, ob sich der »Stalinismus nach Stalin« wandeln könnte. Zudem enthielten einige Veröffentlichungen auch detaillierte Informationen zur zurückliegenden Geschichte der Sowjetunion - wie zum Beispiel zur Rolle des Geheimdienstes und einzelnen Funktionären.

Diese umfangreiche Diskussion implizierte freilich im Laufe der Zeit auch die Frage, inwiefern nach dem Tod Stalins streng genommen noch im Hinblick auf die Analyse des sowjetkommunistischen Regimes von einem totalitären Herrschaftscharakter ausgegangen werden kann und ob in diesem Zusammenhang der Begriff des Stalinismus noch anzuwenden sei. Zudem wurde die grundsätzliche Frage beleuchtet - die

490 Siehe Leonhard, Kreml ohne Stalin, S. 271.

491 Vgl. neben den bereits genannten Veröffentlichungen aus der (Forschungs-)Literatur zum Thema »Zwangsarbeit« und sowjetische Konzentrationslager exemplarisch: Toni Sender, Zwangsarbeit, in: Ost-Probleme 2 (1950), Nr. 12, S. 385-388; Materialien zur Frage der Zwangsarbeit, in: Ost-Probleme 2 (1950), Nr. 35, S. 1107-1110 (Erstveröffentlichung: Journal de Ceneve, Cenf, 18. August 1950); Elinor Lipper, Elf Jahre in Sowjetgefängnissen und Lagern, Zürich 1950; Marta Rudzka, Workuta. Weg zur Knechtschaft, Zürich 1948; H. S., Bericht über sowjetische Lager - bearbeitet auf Crund der offiziellen Protokolle der Internationalen Kommission zum Kampf gegen das Regime der Konzentrationslager, in: Ost-Probleme 3 (1951), S. 1162-1183. 
vor allem in den "traditionellen« Totalitarismustheorien eine wichtige analytische Bedeutung hatte -, welche Rolle die Geheimpolizei im sowjetkommunistischen Herrschaftssystem spielt. Naheliegenderweise ging es um die sich aufdrängende Frage, wer aller Voraussicht nach sich im "Kampf der Rivalen« durchsetzen und mithin Nachfolger des ehemaligen (totalitären) Parteidiktators werden würde. Die Frage, inwiefern es sich beim sowjetkommunistischen Herrschaftsregime in der Nachstalinära noch um ein totalitäres System handelte und mithin der Terror nicht mehr die alles überragende Rolle besaß, bekam explizit und implizit nach der Geheimrede von Chruschtschow auf dem XX. Parteitag der KPdSU im Jahre 1956 sowie nach den Revolutionen in Ungarn und Polen im selben Jahr »neue Nahrung«.

Im Folgenden geht es in erster Linie darum, die oben angesprochene politische und theoretische Diskussion im Monat nachzuzeichnen. Da es nicht möglich ist, diese umfangreiche und facettenreiche Diskussion - das betrifft sowohl die qualitative als auch die quantitative Dimension - aus den Jahren 1953 bis 1960 in Gänze abzudecken, muss demnach der Schwerpunkt auf einzelne exemplarische Veröffentlichungen und Autoren gelegt werden, die auf der Grundlage der zeitgenössischen Forschungsergebnisse kommentiert werden.

Bereits im Aprilheft des Jahres 1953 erschien im Monat aus Anlass des Todes von Stalin am 5. März, neben Lüthys kurzen Ausführungen in seinem Artikel Die Hüter des Mausoleums, ${ }^{492}$ der Beitrag Stalins Vermächtnis. Zur Interpretation seiner letzten Schrift von Löwenthal. Diese »Ministudie« besaß vor allem deshalb eine historisch-analytische Bedeutung, weil sie unmittelbar nach dem in der Märzausgabe erschienenen Beitrag Der Hintergrund der Säuberungen veröffentlicht wurde und insofern die dort angestellten substanziellen Reflexionen, Einschätzungen und Interpretationen zum kommunistischen Herrschaftssystem, zur Rolle Stalins im sowjetischen Einparteienregime sowie zur Bedeutung der stalinistischen internationalen Säuberungen im Nachhinein vom Autor präzisiert werden konnten.

$\mathrm{Zu}$ Beginn der zehn Seiten umfassenden Veröffentlichung hob Löwenthal hervor, dass der Tod des Diktators, der die Sowjetunion knapp 30 Jahre lang mit immer wachsender Machtfülle regiert und der über die "Ausdehnung des sowjetischen Machtbereichs in Europa und Asien nach dem zweiten [sic !] Weltkrieg präsidiert« hatte, zwangsläufig eine »Flut von Spekulationen über die Zukunft des bolschewistischen Weltreichs und die wahrscheinlichen Konflikte unter den überlebenden Führern ausgelöst« hatte. Für ihn war eine solche Spekulation umso natürlicher und legitimer, als „Stalin inmitten einer offenbar noch unabgeschlossenen Welle von Säuberungen« verstarb, deren einer "Aspekt unzweifelhaft die Vorbereitung des Machtkampfes unter den Erben der Diktatur war«. Gleichwohl blieben für Löwenthal jenseits derartiger Spekulationen die grundsätzlichen »soziologischen Fragen nach der Eigenart des totalitären Sowjetregimes, nach seinen Triebkräften und Trägern, seiner Dynamik und seinen inneren Konflikten bestehen. "Ihre Untersuchung«, so Löwenthal, "gegründet auf sehr viel umfassenderes Erfahrungsmaterial, als jede Spekulation über Personalfragen sein kann, mag ihrerseits ein Licht auch auf die aktuelle Situation werfen.«Es blieb vom Standpunkt der westlichen Geschichtsschreibung das »zentrale Geheimnis der sowjetischen Revolution«, dass sie noch immer andauerte. »Das Problem«, so Löwenthal, 
ist nicht einfach, daß das durch die Revolution geschaffene Regime in irgendeiner Form die Macht über das russische Reich behauptet hat, auch nicht, daß es noch immer die Fähigkeit besitzt, sich territorial auszudehnen und seine Grundzüge mit Hilfe einer Mischung von physischer Cewalt und ideologische Bekehrung auf neue Länder zu übertragen; es besteht darin, daß das Regime nach fünfunddreißig Jahren weder zerfallen noch zu einem unveränderlichen Gehäuse erstarrt ist, sondern den revolutionären Antrieb zu weiterer Veränderung im Innern ebensowohl wie nach außen bewahrt hat. Selbst seine Krisen und Säuberungen sind nicht wie die Krisen und Konflikte anderer Herrschaftssysteme - sie sind Teil eines fortgesetzten revolutionären Prozesses. Der Bolschewismus scheint wirklich das Rezept der Permanenten Revolution gefunden zu haben. ${ }^{493}$

Löwenthal machte also gleich zu Beginn seines Beitrages zwei grundsätzliche Aussagen: Zum einen stellte er in dieser Veröffentlichung ausdrücklich fest, dass Stalin in der zurückliegenden Phase der sowjetischen Geschichte, also in den vergangenen knapp 30 Jahren, das bolschewistische Regime zu erst als Diktator und im Laufe der Zeit - so könnte man sagen - als unumstrittener Führer regiert hat; insofern war dies im Hinblick auf die Rolle Stalins in der sowjetischen Führungsriege eine klare Präzisierung im Vergleich zu dem Beitrag Der Hintergrund der Säuberungen, wo letzten Endes dieser Punkt nicht eindeutig zum Ausdruck kam. Zum anderen stellte er fest, dass der Tod Stalins im Grunde genommen am Wesen des Sowjetkommunismus, an der Natur des bolschewistischen Herrschaftssystems nichts verändert hatte, denn durch die Tatsache, dass die Triebkraft weiterhin das »Gesetz der permanenten Revolution« sei, handelte es sich folglich auch beim Nachstalinismus um ein (dynamisches) totalitäres System.

Nach einem Exkurs zum »Gedanke[n] der Permanenten Revolution« bei Marx, Trotzki und Stalin ${ }^{494}$ Beleuchtete Löwenthal den hier $\mathrm{zu}$ interessierenden Sachverhalt über die Zukunft der Sowjetunion. Hierbei war für ihn die wichtigste Frage für das "Verständnis der sowjetischen Politik von heute « darum: "Wie ist die permanente Revolution von oben möglich? Was inspiriert sie, wer sind ihre Träger, mit welchen Mitteln halten sie den Prozeß in Gang, und was sind die sinneren Widersprüche eines solchen Systems - die inneren Konflikte und Spannungen, die es hervorruft? « ${ }^{495}$

Vor dem Hintergrund einer substanziellen Auseinandersetzung über die Bedeutung, die Stalins letzte »theoretische Publikation«, d. h. der am Vorabend des 19. Kongresses der KPdSU im Oktober 1952 erschienenen Broschüre über Ökonomische Probleme des Sozialismus in der UdSSR, für die konkrete politische Praxis der Sowjetunion hatte, versuchte er den aufgeworfenen Fragenkomplex zu beantworten. Hierbei ging er ausführlich auf die kommunistische Ideologie im Allgemeinen und auf das "politische Testament« Stalins, d.h. das langfristige politökonomische »Programm» der permanenten Revolution mit dem Ziel der klassenlosen kommunistischen Gesellschaft, im Besonderen ein; ${ }^{496}$ unter anderem schrieb Löwenthal zum Grundsatz der

493 Richard Löwenthal, Stalins Vermächtnis. Zur Interpretation seiner letzten Schrift, in: Der Monat 5 (1953), H. 55, S. 16-25, hier S. 16.

494 Siehe im Einzelnen ebd., S. $16 \mathrm{f}$.

495 Ebd., S. 17.

496 Siehe im Einzelnen ebd., S. 17-24. 
"Stalin-Broschüre«, dass auch »die Sowjetgesellschaft objektiven ökonomischen Gesetzen unterworfen sei, die man studieren müsse, um mit Hilfe einer richtigen Politik die gesellschaftlichen Kräfte den gewünschten Zielen dienstbar zu machen « ${ }^{497}$ In diesem Zusammenhang machte Löwenthal den Versuch einer substanziellen Analyse des sowjetkommunistischen Herrschaftssystems, d. h. zum Aufbau der führenden Parteiund Staatsinstitutionen in der Sowjetunion sowie dem zugrundeliegenden Verhältnis ebendieser Institutionen untereinander - sowohl in den Monaten vor Stalins Tod als auch danach -, um unter anderem die künftige sowjetische innen- und außenpolitische Entwicklung sowie den innerparteilichen Machtkampf nach Stalins Tod zu thematisieren. Hierzu schrieb Löwenthal:

Mehr noch als Stalins Broschüre selbst zeigte die Einberufung des ersten Parteikongresses [im Oktober 1952] nach dreizehnjähriger Pause, daß die Partei das Bedürfnis empfand, gegenüber den konservativen Tendenzen der Bürokratie ihre eigene Rolle als Träger der politischen Dynamik des Regimes erneut sichtbar zu machen. Dies ist auch der Schlüssel zu der doppelten Reorganisation der obersten Partei- und Staatsorgane im Laufe von wenigen Monaten - auf dem Parteitag und jetzt wiederum nach Stalins Tod.

Bis zum Parteitag war das höchste politische Leitungsorgan der Partei das Politbüro des Zentralkomitees; mit einer Mitgliedschaft von 9 bis maximal 15, einschließlich der Kandidaten, hatte es sich viele Jahre lang als das Gremium bewährt, in dem Stalin alle politischen Probleme mit seinen engsten Mitarbeitern erörtern konnte. In den letzten Jahren war es fast identisch mit dem inneren Kabinett, der Körperschaft der mit dem Titel »Stellvertretender Ministerpräsidenten« ausgezeichneten, jeweils mehrere Ministerien kontrollierenden Koordinatoren, verstärkt gewöhnlich um das formelle Staatsoberhaupt, den Vorsitzenden des Präsidiums des Obersten Sowjets, ein oder zwei Vertreter des Parteisekretariats und meist auch den Ministerpräsidenten der Ukraine. So hatte jedes Mitglied des Politbüros, abgesehen von seinen persönlichen Fähigkeiten, Cewicht als verantwortlicher Leiter eines großen Sektors des gesellschaftlichen Lebens; der Parteiapparat, vertreten durch das Sekretariat, stand dabei als ein solcher Sektor gleichberechtigt neben Armee, Polizei, Diplomatie, Wirtschaftsapparat und Sowjetverwaltung. So wenig wie jene andern Säulen des Sowjetstaates hatte das Sekretariat in normalen Zeiten die Aufgabe, eigene Politik zu machen - es war dazu da, im Sektor der Partei die Politik des Politbüros durchzuführen. Doch es war freilich nicht vergessen, daß einst Stalin sich von dieser Schlüsselposition aus die Führung im Politbüro und die Kontrolle der Staatsmacht gesichert und sie bis zum Kriege sogar unter Verzicht auf einen offiziellen Regierungsposten besetzt hatte: In der kritischen Periode des Kampfes um die Nachfolge Lenins hatte sich die Parteimaschine als der eigentliche Träger des Regimes und der Posten des Generalsekretärs als die all-beherrschende Machtstellung erwiesen.

Im nächsten Absatz schrieb er:

Die auf dem Parteitag vorgenommene Reorganisation ersetzte scheinbar die Alleinherrschaft des Politbüros durch eine Art von Cewaltenteilung: die ungefähre Identi- 
tät von innerem Kabinett und Parteiführung wurde aufgehoben. Statt dessen wurde das Parteisekretariat von früher 3 bis 5 auf annähernd 10 Mitglieder erweitert, die nun mit den Angehörigen des inneren Kabinetts und den wichtigsten andern Würdenträgern nur noch im »Präsidium« der Partei, einer Körperschaft von 25 Mitgliedern und 11 Kandidaten, zusammentrafen. Das neue Präsidium war offenkundig zu groß, um laufende politische Entscheidungen in der Art des alten Politbüros zu treffen: es war eine Scheinkörperschaft zur Herstellung eines repräsentativen Cleichgewichts zwischen Staatsführung und Parteiapparat. Das wirkliche Geheimnis der Reorganisation war einerseits, daß zum erstenmal seit den großen Säuberungen der dreißiger Jahre das Sekretariat als engstes und damit oberstes Leitungsorgan der Partei, als Träger einer selbständigen politischen Initiative hervortrat; und andererseits, daß die Koordination zwischen Partei und Regierung, in einem Gremium von 36 Mitgliedern und Kandidaten unmöglich, nun an den zwei Personen hing, die sowohl dem Sekretariat wie dem inneren Kabinett angehörten: Stalin und Malenkow.

Es war die Vorbereitung großer Entscheidungen unter dem Schein des Kompromisses. Unter dem Schein des Gleichgewichts von Partei- und Staatsapparat - Wiederherstellung der selbstständigen politischen Rolle des Parteiapparats; unter dem Schein des Respektes für die traditionelle Rangordnung, in der Molotow zu Lebzeiten Stalins sein erster Stellvertreter in der Regierung war - Sicherung der Nachfolge Malenkows, seines ersten Vertreters im Parteisekretariat, als Beherrscher von Partei und Staat. ${ }^{498}$

Vor dem Hintergrund seiner bisherigen Ausführungen ging Löwenthal dann ausführlich auf die seiner Auffassung nach tatsächlichen sowie möglichen politischen Implikationen des Todes von Stalin für das »neue« sowjetkommunistische Regime ein. Sofort nach dem Tode Stalins schrieb er,

sind in einer erneuten Reorganisation die Schleier weggerissen und der Kern der neuen Machtverhältnisse bloßgelegt worden. Auf der einen Seite ist eine außerordentliche Konzentration der Regierungsgewalt erfolgt: man hat nicht nur die Anzahl der Ministerien halbiert - die allerdings für praktische Vollsitzungen des Ministerrats noch immer zu groß bleibt -, sondern man hat auch das alte »Präsidium des Ministerrates« abgeschafft und ein halbes Dutzend wichtiger Minister des Titel eines "Stellvertretenden Ministerpräsidenten« beraubt. Die einzige effektive Exekutivkörperschaft ist jetzt das neue Präsidium aus nur fünf Mitgliedern: Malenkow, als Ministerpräsident und Parteiführer, und seine vier verantwortlichen Stellvertreter für Polizei, Außenpolitik, Verteidigung und wirtschaftspolitische Koordinierung. Die nächste politische Körperschaft, der diese fünf verantwortlich sind, ist bereits keine Regierungsinstanz mehr, sondern eine reine Parteiinstanz - das unter dem neuen Namen »Präsidium des Zentralkommitees « wiedererstandene Politbüro von zehn Mitgliedern und vier Kandidaten, in dem sie mit einigen der wichtigsten Ressortminister, dem neuen Staatschef und den Vertretern des Parteiapparats zusammentrafen.

Mit dieser Verwirklichung des Primats der Partei und der Person Malenkows, in der es sich verkörpert, tritt das Sekretariat wieder mehr in den Hintergrund, bleibt aber als Reserveposition für etwaige neue Auseinandersetzungen weiterhin bestehen. [...] 
Es ist hier bisher nicht ausdrücklich von dem Problem der Säuberungen die Rede gewesen, deren Wellen in den letzten Monaten vor Stalins Tod von den Satellitenstaaten erneut auf die Sowjetunion zurückschlugen. Wir glauben, daß es in den blutigen Auseinandersetzungen, neben zahlreichen schwer durchschaubaren persönlichen Rivalitäten, um drei große Cruppen von politischen Fragen ging und geht. Die erste ist das andauernde Suchen nach einer realistischen sowjetischen Außenpolitik, die für eine ganze Periode an die Stelle der gescheiterten Abenteuerpolitik Shdanows treten könnte. Die zweite dreht sich um das Anwachsen des großrussischen Nationalismus und Zentralismus, sowohl den Satelliten gegenüber wie innerhalb Rußlands, und die daraus entspringenden Maßnahmen sowohl gegen jeden nichtrussischen Nationalismus innerhalb des Sowjetreichs wie gegen »jüdisches Kosmopolitentum«. Die dritte ist eben jener Kampf der Partei um die Behauptung der eigenen Initiative und die Durchführung der nächsten Stufe der inneren Revolution.

In diesem Zusammenhang ging Löwenthal dann zum Abschluss auf die zu Beginn seiner Studie formulierten Fragen ein und meinte, dass er nicht einmal versuchsweise andeuten könne, »wie diese Fragen sich in den heutigen Machtkämpfen unter den bolschewistischen Führern verflechten und $\mathrm{zu}$ Gruppenbildungen führen mögen«. Indes sollte seiner Auffassung nach vor einem "naheliegenden Mißverständnis«, so Löwenthal,

gewarnt werden - vor der Annahme, die eifrigsten Befürworter der Parteiherrschaft und der nächsten Schritte der inneren Revolution müßten auch die schärfsten Verfechter einer aggressiven revolutionären Expansion nach außen sein, und umgekehrt. [...] Zum bisher letzten großen Schritt in Rußlands innerer Revolution - der Fusion der Kolchosen zu größeren Einheiten - wurde angesetzt, als die Periode der shdanowistischen Expansion zu Ende ging; und manches spricht dafür, daß es auf der heutigen Stufe der sowjetischen Entwicklung sich nicht um die Weiterführung der Revolution oder Stabilisierung, sondern vorerst nur zwischen der Konzentration der revolutionären Entwicklung nach innen oder außen handelt. ${ }^{499}$

Ohne Zweifel stellten die Ausführungen von Löwenthal in seinem Beitrag Stalins Vemächtnis auch und vor allem eine substanzielle Analyse des komplizierten Aufbaus des sowjetischen Herrschaftsregimes sowie den Versuch dar, in dem Dschungel der miteinander konkurrierenden Partei- und Staatsapparate gewissermaßen Klarheit herzustellen. Wie gezeigt werden konnte, ging es dem Autor insbesondere darum, den Scheinwerfer auf die nach dem Tod Stalins entstandenen neuen Machtverhältnisse in der sowjetischen Führung zu richten.

In diesem Zusammenhang gelangten Löwenthal wichtige Erkenntnisse, die für die Beschreibung und Analyse der Geschichte des Sowjetkommunismus im Monat von größter Bedeutung waren. So thematisierte der Kommunismusexperte beispielsweise, wie es Stalin gelang, nach dem Tod von Lenin seine damalige Funktion als Generalsekretär des ZK der KPdSU zu nutzen, um allmählich seine Macht so auszubauen, dass er im Grunde genommen imstande war, über die Partei, das Zentralkomitee, das Politbüro und weitere Parteigremien allein zu herrschen. Anders gesagt, Stalin besaß 
in der zurückliegenden Geschichte des sowjetischen Staates eine einzigartige, unumstrittene Machtposition, die - so können die Ausführungen Löwenthals interpretiert werden - das Funktionieren des stalinistischen Systems möglich machten und erklärten. Überhaupt auf die zentrale politische Bedeutung des sogenannten Sekretariats, nämlich als Vertretung der Partei und gleichberechtigte Institution neben den anderen zentralen Säulen des Sowjetstaates (Armee, Polizei, Diplomatie, Wirtschaftsapparat und Sowjetverwaltung), sowie auf die Veränderung im sowjetischen Herrschaftsgefüge im Laufe der Zeit zu insistieren, waren wichtige Detailerkenntnisse.

Löwenthal konnte zudem zeigen, dass sich Stalin in den Monaten vor seinem Tod eine weitere Veränderung des Partei- und Staatsapparates zum Ziel gesetzt hatte. Denn sein Hinweis, dass das Parteisekretariat auf dem XIX. Parteitag im Oktober 1952 auf annähernd zehn Mitglieder vergrößert wurde, war ein expliziter Hinweis darauf, dass die Macht des Sekretariats weiter ausgebaut wurde, und eine impliziter Hinweis darauf, dass gleichzeitig das Politbüro an Macht verlor. ${ }^{500}$ Selbstverständlich war es, wie es Löwenthal auch ausdrücklich konstatierte, zum damaligen Zeitpunkt unmöglich, unmittelbar nach dem Tod Stalins "sichere Erkenntnisse« in Bezug auf die mögliche zukünftige (revolutionäre) sowjetische Innen- und Außenpolitik im Allgemeinen zu liefern und den Ausgang des für ihn ohne Zweifel bereits in Gang gekommenen innerparteilichen Machtkampfes unter den bolschewistischen Führern im Besonderen vorherzusagen. Indes: überhaupt die konkreten Veränderungen im komplizierten Verhältnis von Partei- und Staatsapparat der Sowjetunion nach Stalins Tod zu fokussieren, war ein wichtiger Beitrag zur Analyse des Sowjetkommunismus. Im Zusammenhang mit der Thematisierung der erneuten Reorganisation konnte Löwenthal die wichtige Feststellung treffen, dass es die - man könnte sagen - erste Maßnahme der neuen sowjetischen »kollektiven Führung « war, die zentrale Macht des Parteisekretariats zurückzuschrauben, um einerseits die Regierungsgewalt im eigentlichen Sinne und andererseits die Macht des Politbüros wieder zu stärken. Hinzu galt nach Auffassung von Löwenthal fortan der Primat der Partei, und das bedeutete konkret, dass sich die KPdSU, die sich unter Stalin in einen dem sowjetischen Führer blind gehorsamen Apparat verwandelt hatte, wieder zu einem tatsächlichen politischen Faktor in der Gesellschaft entwickeln wird.

Allerdings konnte Löwenthal bereits darauf hinweisen, dass im Zuge der erneuten Reorganisation der Sowjetregierung und der Parteiführung es zu einer Streichung der Hälfte der Ministerien kam und dass erstens die Sowjetunion fortan von der "einzige[n] effektive[n] Exekutivkörperschaft« regiert werden wird, nämlich vom neuen Präsidium, bestehend aus fünf Mitgliedern, mit Malenkow als Vorsitzendem an der Spitze, sowie zweitens, dass in dieser »kollektiven Führung « ein schwer zu durchschauender interner Machtkampf - der in seinen Augen bereits vor dem Tod Stalins in Gang kam - zu erwarten sei, der sich so oder so auf die Innen- und Außenpolitik des »neuen « Regimes auswirken wird; in welcher konkreten Form dies sein würde, musste zum Zeitpunkt der Veröffentlichung des Beitrages freilich offen bleiben. ${ }^{501}$

Bereits in der nächsten Ausgabe des Monat, also im Maiheft des Jahres 1953, ging Erik Nohara sowohl auf die tatsächlichen politischen Folgen, die sich in den letzten Wochen für »Außenstehende« konkret abzeichneten, als auch auf die möglichen poli-

500 Vgl. hierzu auch: Zurück zum Politbüro, in: Ost-Probleme 5 (1953), Nr. 17, S. 530-534.

501 So auch die Auffassung des anonymen Autors, in: Ebd., S. 534. 
tischen Folgen des Todes von Stalin für das sowjetische Herrschaftssystems ein. Vor dem Hintergrund einer Auseinandersetzung mit zahlreichen Veröffentlichungen zu ebendiesem Thema in verschiedenen internationalen Tageszeitungen und Zeitschriften von renommierten Kommunismusexperten - u.a. Borkenau, Löwenthal, Weißberg-Cybulski, Crankshaw, Nikolajewski, Souvarine und Lüthy - schrieb Nohara am Ende seines Beitrages Zwei Monate ohne Stalin (und bestätigte im Nachhinein im Grunde genommen indirekt im Wesentlichen die von Löwenthal gemachten Einschätzungen aus Stalins Vermächtnis bzw. präzisierte sie aufgrund neuer Informationen): »Rund zwei Monate«, so Nohara,

sind seit Stalins Tod vergangen. Noch dürfte es kaum möglich sein, genau und im Detail zu sagen, welche Konsequenzen sich aus diesem Ergebnis ergeben. Dies heißt jedoch gewiß nicht, daß den Prognosen und Analysen der politischen Beobachter nur eine rein hypothetische Bedeutung beizumessen sei. Was kann man als Extrakt aus den so verschiedenen Kommentaren der Presse gewinnen? Drei Feststellungen lassen sich schon heute treffen: erstens steht mit einiger Cewißheit fest, daß der Tod des Diktators, wie erwartet, von inneren Machtkämpfen begleitet war; zweitens haben die Nachfolger es ganz offensichtlich für ratsam gehalten, zumindest zeitweilig mit den alten Methoden der Außenpolitik zu brechen und für eine vorteilhaftere »publicity « des Regimes zu sorgen; drittens wird ohne Zweifel der Regierungswechsel den sozialen und wahrscheinlich auch den politischen Aufstieg neuer Schichten innerhalb der sowjetischen Cesellschaft beschleunigen.

Mit Stalin scheint der monolithische Charakter des Regimes dahingegangen; deutlicher als zuvor zeichnen sich vier Gruppen - die Bonzen der Partei, die Offiziere der Armee, die Manager der Wirtschaft und die Kommissare der Polizei - als Kandidaten für die oberste Machtposition ab. ${ }^{502}$

In der sowjetischen Besatzungszone geriet wiederum das SED-Regime unter Ulbricht im Juni 1953 durch den »Arbeiter- und Bauernaufstand« massiv unter Druck. ${ }^{503}$ Für die politischen Beobachter des Monat war dies auch und vor allem ein Symptom dafür, dass sich nach dem Tod Stalins die neue sowjetische Führung im Hinblick auf den zukünftigen außenpolitischen Kurs im Kontext des Kalten Krieges noch nicht eindeutig festgelegt hatte und dafür, dass ebendiese Außenpolitik mit den tatsächlichen weitreichenden innenpolitischen Veränderungen des sowjetischen Herrschaftssystems nach dem Tod Stalins in einem direkten Zusammenhang stand. Im Zuge der veränderten Führungsstruktur der Sowjetunion trat an die Stelle des »allmächtigen Diktators« das Prinzip der »kollektiven Führung«. Malenkow übernahm - wie von Löwenthal angesprochen wurde - das Amt des Ministerpräsidenten (sowie vorläufig das Amt des Generalsekretärs des ZK der Partei) und angesichts der Zusammenlegung zahlreicher Ministerien übernahm Molotow die auswärtigen Angelegenheiten; Berija wurde zum stellvertretenden Ministerpräsidenten und Innenminister ernannt und blieb somit an der Spitze der staatlichen Sicherheitsapparate. Neben Woroschilow

502 Erik Nohara, Zwei Monate ohne Stalin, in: Der Monat 5 (1953), H. 56, S. 200-206, hier S. 206.

503 Vgl. hierzu vor allem Ernest ]. Salter, Über den Juni-Aufstand, in: Der Monat 5 (1953), H. 59, S. 545548, sowie Der Aufstand im Juni. Ein dokumentarischer Bericht (Teil 1), in: Der Monat 5 (1953), H. 60 , S. 595-624 und Teil 2, in: Der Monat 5 (1953), H. 61, S. 45-66. 
und Kaganowitsch rückte der Kriegsminister Bulganin sowie der Parteisekretär von Moskau, Chruschtschow, in die Führungsspitze des sowjetischen Staates und der Partei auf. Wobei die eigentliche Macht im Rahmen der »kollektiven Führung« im Grunde genommen in den Händen der drei Personen umfassenden "Zweckgemeinschaft» Malenkow/Berija/Chruschtschow lag. Damit wurde das stalinistische Führungsprinzip und mithin die zentrale Voraussetzung des stalinistischen Herrschaftssystems grundsätzlich geändert. Bereits Anfang April 1953 trat Malenkow seine Funktion als Sekretär des ZK der KPdSU an Chruschtschow ab. Ende Juni 1953 wurde überraschend Berija verhaftet. Damit war nicht nur ein Rivale um die Nachfolge Stalins ausgeschaltet. Denn neben der weiteren Veränderung in der unmittelbaren sowjetischen Führung war dies ein Anzeichen dafür, dass in der sowjetischen Führungsgruppe über die Frage des zurückliegenden bzw. zukünftigen Kurses in der Innen- und Außenpolitik ein essenzieller Dissens bestand sowie dafür, dass sich das Regime weiterhin in einer grundsätzlichen Krise befand..$^{504}$

Angesichts dieser angesprochenen zugespitzten innen- und außenpolitischen Entwicklung in den unmittelbaren Monaten nach dem Tod Stalins veröffentlichte Löwenthal im September 1953 im Monat seinen Beitrag Am Ende einer Epoche. Die Umwälzungen im russischen Großreich ${ }^{505}$ der sich mit »sämtlichen Ereignissen « auseinandersetzte und versuchte, die Bedeutung dieser für das sowjetkommunistische Regime einzuschätzen. Im Folgenden werden längere Passagen aus diesem Beitrag referiert bzw. zitiert und am Ende kommentiert. Für Löwenthals Beitrag sprachen zwei Gründe: Einerseits hob er sich aufgrund seines substanziellen analytischen und interpretatorischen Ansatzes im Vergleich zu anderen Veröffentlichungen im Monat hervor, ${ }^{506}$ andererseits löste er anschließend eine interne, durchaus kontroverse Diskussion unter den Kommunismusexperten der Zeitschrift aus. ${ }^{507}$

Vor dem Hintergrund einer neuerlichen Thematisierung der kommunistischen Ideologie leninscher (neue ökonomische Politik) und stalinscher (»Doktrin vom >Aufbau des Sozialismus in einem Lande«) Provienenz und der genauen Beschreibung, wie sich die (welt-)revolutionäre Theorie des unüberbrückbaren Systemgegensatzes von »sowjetkommunistischer Welt« und »kapitalistischer Welt« im jeweiligen zeitlichen Kontext auf die Innen- und Außenpolitik des bolschewistischen Regimes im Laufe der Jahrzehnte und speziell im Kalten Krieg ausgewirkt hatte, ${ }^{508}$ schrieb Löwenthal unter der Überschrift Bruch mit der stalinschen Tradition:

Das grundlegende politische Problem aber stellt der neue Kurs in Rußland selbst; denn obwohl hier keine Fehler ausdrücklich zugegeben wurden - die Umstellung wird im Gegenteil mit der Cröße der bisherigen Errungenschaften, mit der Höhe des erreichten

504 Vgl. Leonhard, Kreml ohne Stalin, S. 106-116.

505 Richard Löwenthal, Am Ende einer Epoche. Die Umwälzungen im russischen Großreich, in: Der Monat 5 (1953), H. 60, S. 572-580.

506 Vgl. exemplarisch Hugh Seton-Watson, Sowjetrußlands neue Bourgeoisie, in: Der Monat 5 (1953), H. 58, S. 417-421.

507 Vgl. hierzu Franz Borkenau, Was geschieht in Sowjetrußland, in: Der Monat 6 (1953), H. 62, S. 213-215; Alfred Burmeister, Der Stalinismus bleibt!, ebd., S. 215 f. sowie Richard Löwenthal, Antwort des Autors, ebd., S. 216-219.

508 Siehe im Einzelnen Löwenthal, Am Ende einer Epoche, in: Der Monat 5 (1953), H. 60, S. 573-578. 
Niveaus der Schwerindustrie begründet -, steht dieser Kurs im klaren Gegensatz zur stalinschen Doktrin, wie sie noch am Vorabend des 19. Parteitags in den Ökonomischen Problemen des Sozialismus« verkündet wurde. Stalin bezeichnete die Priorität der Produktion von Produktionsmitteln, d. h. die Politik der schrankenlosen Akkumulation und Rüstung auf Kosten des Lebensstandards der Bevölkerung, als ein Grundkennzeichen des Sozialismus; Malenkow zeigt, daß dieses Übergewicht absurde Proportionen erreicht habe, und verspricht Änderung.

Da sich nach Auffassung von Löwenthal unter Malenkow nicht zuletzt auch gravierende Veränderungen in der sowjetischen Landwirtschaftspolitik ankündigten - dadurch, dass den ehemaligen sogenannten Kollektivbauern ein größerer Spielraum für individuelle wirtschaftliche Aktivitäten gewährt zu werden schien -, stellte er grundsätzlich fest:

Daraus wird deutlich, daß wir es bei dem »neuen Kurs« nicht nur mit einem erzwungenen Rückzug in der Wirtschafts- und Außenpolitik zu tun haben, sondern gleichzeitig mit einem bewußten Bruch der Nachfolger mit der staatlichen Tradition und Doktrin. Der Bruch erfolgt bisher ohne offene Polemik und ist kein Bruch mit den ursprünglichen Grundzügen des bolschewistischen Parteiregimes: jeder Schritt geschieht (wie in den ersten Jahren bei Tito!) unter Berufung auf Lenin und unter Berufung auf die führende Rolle der Partei. Aber zum mindesten ist durch das Zusammentreffen des außen- und wirtschaftspolitischen Rückzugs mit der Nachfolgekrise der Charakter des Parteiregimes zum erstenmal seit der Konsolidierung der Herrschaft Stalins in Fluß gekommen. $^{509}$

Mit diesen Ausführungen machte Löwenthal deutlich:

1. Dass sich nach dem Tod Stalins an der grundsätzlichen Natur des sowjetkommunistischen Systems auf den ersten Blick nichts Entscheidendes geändert hatte, denn es handelte sich weiterhin um ein revolutionäres Einparteienregime, deren führende Funktionäre in der politisch-ideologischen Tradition Lenins und Stalins standen und mithin das eigentliche Ziel - Einführung des sowjetischen Kommunismus in der ganzen Welt aufgrund eines in ihren Augen existenziellen, d. h. unüberbrückbaren Gegensatzes zur kapitalistischen nichtsowjetischen Welt - nicht aufgegeben hatten.

2. Dass sich gleichwohl in den ersten Monaten des "neuen Regimes« eine wichtige Differenz zu der Herrschaftsära Stalins abzeichnete, als nämlich die neuen Machthaber in Gestalt von Malenkow bereits ankündigten, dass sie innenpolitisch den »Bruch mit der stalinschen Tradition« anvisierten, und zwar insofern, als sie in der Wirtschaftspolitik unter anderem den Schwerpunkt auf eine Erhöhung der Konsumproduktion zulasten der Rüstungsproduktion zu legen gedachten sowie in der landwirtschaftlichen Produktion das Ziel hatten, den »totalitären Mantel« $\mathrm{zu}$ öffnen.

3. Dass im Hinblick auf die Außenpolitik aus der für Löwenthal geplanten veränderten Wirtschaftspolitik folgte - so lassen sich die Ausführungen implizit lesen -, 
dass das »Nach-Stalin-Regime« fortan eher eine abwartende, vorsichtigere Politik favorisiert, die der Sicherung des sowjetischen Territoriums den Vorrang vor militärischen Expansionsbestrebungen einräumt.

In dem Abschnitt »Abbau des Super-Apparats« seines Beitrages ging Löwenthal ausführlich auf wesentliche Merkmale des Einparteienregimes stalinscher Couleur ein, um nicht zuletzt die mögliche künftige Entwicklung des »neuen« sowjetischen Herrschaftssystems zu thematisieren. Hierzu schrieb er angesichts der in den zurückliegenden knapp sechs Monaten nach dem Tod Stalins in Gang gekommenen Veränderungen in der sowjetischen Innenpolitik:

Was können wir heute schon über die Faktoren und Tendenzen dieser in Fluß gekommenen Entwicklung sagen?

Zunächst: der ideologische Bruch mit der stalinschen Tradition wurde dadurch unvermeidlich, daß Stalin zu seinen Lebzeiten - und wichtige Träger seines persönlichen Herrschaftsapparates noch nach seinem Tode - sich dem notwendig gewordenen Rückzug widersetzten. Um das riesige bürokratische Staatsgebilde der Sowjetunion mit den divergierenden Eigentendenzen seiner verschiedenen Machtapparate - Partei, Polizei, Armee, Wirtschaft, Sowjetverwaltung -zusammenhalten und einheitlich beherrschen zu können, hatte Stalin seinen persönlichen Super-Apparat entwickelt, dessen Angehörige in allen Teil-Apparaten sein unmittelbares Eingriffsrecht sicherten und ihre »Vorgesetzten «kontrollierten. Der Kern dieses Apparates war ein persönliches Sekretariat aus Hunderten von Menschen, verbunden mit bestimmten Sektoren des militärischen und zivilen Geheimdienstes. [...]

Seit Stalins Tod ist dieser Super-Apparat zerschlagen worden; die neue Lehre von der kollektiven Führung war die Begründung dafür und zugleich der Beginn des ideologischen Bruchs mit dem Stalinismus. Die ehemals führenden Exponenten des persönlichen Sekretariats, wie Poskrebyschew und der Leiter der Zentralen Kontrollkommission, Schkirjatow, sind seither nicht öffentlich erschienen; die Anklage gegen die Ärzte wurde als verbrecherische Fälschung erklärt; [...].

Zweitens: obwohl die neue Entwicklung von der Parteiführung eingeleitet worden ist, schwächt sie zunächst unvermeidlich deren Autorität und stärkt die Selbständigkeitstendenzen der neuen bürokratischen Oberschicht der Gesellschaft. Dies einmal, weil keine Diktatur ohne unumstrittene persönliche Spitze stabil sein kann - kollektive Führung an der Spitze einer Diktatur bedeutet die Tendenz zur Rivalität der Teilapparate und zur Erschwerung von klaren Entscheidungen, bis entweder die Diktatur zerfällt oder einer der Rivalen eindeutig als Sieger dasteht. ${ }^{510}$

Nachdem Löwenthal in diesem Kontext darauf hinwies, dass Berija im »offenen Machtkampf« um die Nachfolge Stalins seinen parteiinternen Konkurrenten, d. h. seinen Rivalen aus der »neuen kollektiven Führung « unterlegen und im Anschluss daran, so Löwenthal, »verschwunden« war, stellte er im folgenden Absatz fest: 
Zugleich bedeutet der wirtschaftliche Rückzug, das Nachlassen des Druckes auf die Bevölkerung, als solcher eine Ermutigung der Selbständigkeitstendenzen aller gesellschaftlichen Kräfte, ihrer Sehnsucht, den Druck der »permanenten Revolution « nicht nur zeitweise einzuschränken, sondern ein für allemal abzuschütteln, was nur durch Auflösung oder Sturz des Parteiregimes möglich ist. Seit Lenins »Neuer Ökonomischer Politik«, die noch von einem Führer mit unumstrittener Autorität begonnen wurde, hat es keine längere Phase der Lockerung des ökonomischen Drucks in der Sowjetunion gegeben [...].

Drittens: im Kampf gegen diese natürliche Tendenz der neuen Sowjetgesellschaft, die Krise zur Abschüttelung des Parteiregimes zu benutzen, bedienen sich Malenkow und die Parteiführung zweier Mittel. Das eine ist der Versuch, den einen Teil des Staatsapparates gegen den anderen auszuspielen - z.B. die neue "gemäßigte« Armeeführung gegen die Polizei -, auf die Gefahr hin, daß gerade dadurch die verschiedenen Machtapparate zu potenziellen Schiedsrichtern in den inneren Auseinandersetzungen der politischen Führung werden. Das andere ist der »titoistische« Appell an die Masse gegen die Bürokratie, der Versuch, die längst von der Diktatur erstickten Selbstverwaltungsorgane der Arbeitenden wieder zu beleben, um so der bürokratischen Oberschicht ein Gegengewicht zu bieten. In den letzten Monaten hat die sowjetische Parteipresse namentlich die Wiedereinführung regelmäßiger Mitgliederversammlungen in den Kolchosen, die Wahl der Kolchosenmanager aus der Mitgliedschaft (d. h. das Verbot der Ernennung von Außenstehenden) und die Wiederaufnahme der längst vergessenen Praxis der »Produktionsberatungen« in den Betrieben der Staatsindustrie gefordert. Auf diese Art kann sich das Parteiregime unter Umständen längere Zeit auch bei einer Politik der Lockerung behaupten, aber nur, indem es sich wesentlich modifiziert. Es scheint, daß die Losung von der Notwendigkeit kollektiver Verantwortung auf allen Stufen neuerdings diesen Sinn bekommen hat. ${ }^{511}$

Für Löwenthal bestanden die Alternativen zu einer solchen Transformation des Regimes entweder in seinem "Sturz durch Elemente der Oberschicht - am wahrscheinlichsten durch eine Militärdiktatur - oder seine erneute Verhärtung zur Parteidiktatur mit persönlicher Spitze im stalinschen Stil nach wiederholten blutigen Auseinandersetzungen. Es scheint uns", so Löwenthal zum Schluss seines Beitrages, »unmöglich, zu prophezeien, was wahrscheinlicher ist [...]. «112

In Löwenthals Ausführungen in dem Abschnitt zum »Abbau des Super-Apparats« seines Beitrages Am Ende einer Epoche. Die Umwälzungen im russischen Großreich aus dem Septemberheft 1953 kam zum Ausdruck, dass sich sechs Monate nach dem Tod Stalins im Hinblick auf die tatsächliche und künftige politische Entwicklung der Sowjetunion unter anderem feststellen bzw. prognostizieren ließ:

1. Dass es durch die neue »kollektive Führung« zu einer tatsächlichen Zerschlagung des ausdrücklich auf Stalin zugeschnittenen totalitären Herrschaftsapparates gekommen war. Eine entscheidende Maßnahme war zum Beispiel die Zerschlagung des Privatsekretariats von Stalin und die Ausschaltung führender Funktionäre 
dieser Institution (wie zum Beispiel Poskrebyschew) ${ }^{513}$ sowie der Geheimdienstapparate, wie Löwenthal zu Recht feststellte. Allerdings wurde von ihm nicht klar hervorgehoben, dass die Säuberung der früher unter der direkten Führung Stalins und nicht unter der Kontrolle der Partei stehenden staatlichen Sicherheitsorgane (u.a. des ehemaligen stellvertretenden Minister für Staatssicherheit und Leiter der Untersuchungsabteilung, Michail Rjumin) seitens der neuen sowjetischen Führung bereits vor der Verhaftung von Berija im Juli 1953 stattfanden, also damit auch von ihm als Chef des ehemaligen NKWD-Apparates mitgetragen wurde. ${ }^{514}$

2. Dass Löwenthal zumindest implizit eine plausible Interpretation für die Verhaftung von Berija lieferte. Bereits zum damaligen Zeitpunkt gab es stichhaltige Ansatzpunkte dafür, dass Berija im Kontext des »offenen Machtkampfes« von seinen Rivalen ausgeschaltet wurde, weil er als Innenminister und mithin als Chef der staatlichen Sicherheitsapparate über eine zu starke exekutive politische Macht verfügte. Obwohl Berija mit Blick auf die gemeinsam von der »kollektiven Führung" getragene politische und ideologische Generallinie keine grundsätzlich divergierende Vorstellung hatte, sollte in jedem Fall ein Rückgängigmachen eines Bruchs mit dem Stalinismus verhindert werden. Diese Gefahr bestand - so könnte man Löwenthal interpretieren - angesichts des direkten Zugriffs Berijas über die staatlichen Sicherheitsorgane, sodass präventiv verhindert werden sollte, dass wie unter Stalin ein von der Partei unabhängiger Machtapparat der (Geheim-)Polizei entstehen könnte. Mithin sollte eine Rückkehr zur stalinistischen Vergangenheit, d. h. die Konstituierung eines Herrschaftssystems stalinscher Provenienz verhindert werden. ${ }^{515}$

3. Dass Löwenthal im September 1953 die in den Monaten vor dem Tod Stalins in Gang gekommenen »internationalen Säuberungen« und die »Anklage gegen die Kremlärzte« - die von ihm zu Recht als »verbrecherische Fälschung« bezeichnet wurde, sodass die nachstalinistische Führung die Angeklagten aus der Haft entließ und rehabilitierte - als eine nicht zu Ende geführte "Zweite Jeshowschtshina« interpretierte, mit der aller Voraussicht nach Stalin die »alte Garde« von Parteifunktionären ausschalten wollte (u.a. in den Sicherheitsorganen), die nur durch den Tod des Kremlchefs nicht abgeschlossen werden konnte.

4. Dass infolge der nach dem Tod Stalins entstandenen neuen historisch krisenhaften Situation - zum einen aus systemimmanenten Gründen und zum anderen durch die notwendig gewordene neue wirtschaftspolitische Ausrichtung des Regimes $^{516}$ - sowohl gesamtgesellschaftliche Kräfte freigesetzt wurden als auch Selbstständigkeitstendenzen des »bürokratischen Apparates« verstärkt hatten, die die Herrschaft des neuen Parteiregimes gleichzeitig unterminierte.

5. Dass in jedem Fall in den darauffolgenden Wochen und Monaten mit ganz entscheidenden innenpolitischen Veränderungen in der Sowjetunion im Allgemeinen und in der Führungsspitze der Partei im Besonderen aufgrund der von Löwenthal

513 So auch die Auffassung von Leonhard, Kreml ohne Stalin, S. 95.

514 Vgl. hierzu ebd., S. 102.

515 Vgl. auch die Interpretation von Boris Nikolaejewski, Zur Soziologie der Macht in der totalitären Diktatur, in: Ost-Probleme 9 (1957), Nr. 28, S. 974-986, hier S. 979-981; Erstveröffentlichung in: Sozialistitscheskij Westnik, Nr. 8-10/1957.

516 Vgl. hierzu im Einzelnen Leonhard, Kreml ohne Stalin, S. 122-133. 
beschriebenen Krisenproblematik zu rechnen sei, die das Wesen des bestehenden Einparteienregimes betreffen würde. Auffallend hierbei war, dass der Kommunismusexperte im Rahmen seiner Prognose, dass drei mögliche Verlaufsformen einer Wandlung des sowjetischen Regimes denkbar seien - neben dem Sturz des Regimes durch die »Elemente der Oberschicht« (genauer gesagt durch die »bürokratische Oberschicht unter militärischer Führung ${ }^{517}$ ) zur Errichtung einer »Militärdiktatur« sowie der neuerlichen »Verhärtung« des Regimes zu einer persönlichen Autokratie einer einzelnen Person - er sogar eine »Modifikation« bzw. »Demokratisierung« des Regimes analog zu der Entwicklung Jugoslawiens unter Tito für denkbar hielt. ${ }^{518}$

6. Dass vor dem Hintergrund der ausdrücklich thematisierten Rolle von Malenkow im Hinblick auf die prognostizierte "potentielle« Entwicklung des Regimes von Chruschtschow keine Rede war. Das war vor allem deshalb bemerkenswert, weil der neue Generalsekretär des ZK der KPdSU mit Malenkow unmittelbar nach der Ausschaltung Berijas die »kollektive Führung« im Grunde genommen durch eine »Dyarchie«(Borkenau) ersetzt hatte. ${ }^{519}$

Dass allerdings Chruschtschow fortan eine überragende Rolle spielte sollte - durchaus in Ansätzen, wie es Löwenthal voraussagte, als er davon sprach, dass es möglicherweise zu einer »erneute[n] Verhärtung zur Parteidiktatur mit persönlicher Spitze im stalinschen Stil, nach wiederholten blutigen Auseinandersetzungen« kommen würde -, zeigte die tatsächliche Geschichte der Sowjetunion in den Jahren nach der Veröffentlichung seines Beitrages im Monat. Allerdings traten auf der anderen Seite nicht zuletzt in der Innenpolitik der Sowjetunion Entwicklungen ein, die der Kommunismusexperte nicht voraussah.

Einerseits war mit der Zerschlagung des auf Stalin zugeschnittenen »Super-Apparats« zweifelsohne bereits im Sommer 1953 das stalinistische Führungsprinzip aufgebrochen. Mithin wurde durch die neue sowjetische Führung eine wesentliche Voraussetzung des gesamten stalinistischen Herrschaftssystems geändert, das nicht zuletzt den (permanenten) Terror vor allem der 1930er-Jahre und die zurückliegenden (internationalen) Parteisäuberungen möglich machte. Andererseits zeigte sich, dass die neue sowjetische Führung, namentlich Malenkow und Chruschtschow, überzeugte »Stalinisten« waren, die die »bewährten« Herrschaftsmethoden anwendeten, um innerparteiliche Rivalen (wie zum Beispiel Berija) und Funktionäre aus dem stalin-

517 So die spätere Präzisierung von Richard Löwenthal, Antwort des Autors: in: Der Monat 6 (1953), H. 62 , S. 216.

$518 \mathrm{Vgl}$. in diesem Zusammenhang die Veröffentlichungen im Monat, die sich mit der»demokratischen « Entwicklung Jugoslawiens unter Tito auseinandersetzten und in deren Fokus die Frage stand, ob es sich beim »Titoismus « um ein totalitäres Regime handelte speziell Richard Löwenthal, Brief aus Belgrad: Modellfall Jugoslawien. Von der Kolchose zur Gemeinschaft, in: Der Monat 6 (1953), H. 62 , S. 125-134, sowie Ernst Halperin, Ist Jugoslawien ein totalitärer Staat?, in: Der Monat 6 (1954), H. 68 , S. 196-199; vgl. unter diesem Aspekt auch Ernst Halperin, Brief aus Belgrad: L'Affaire Djilas. Bericht über einen Ketzerprozeß, in: Der Monat 6 (1954), H. 66, S. 593-604, sowie Richard Löwenthal, Ketzer oder Pionier, in: Der Monat 6 (1954), H. 67, S. 89-91.

519 Vgl. hierzu abschließend das grundsätzliche Resümee: Ein Jahr kollektive Kremldiktatur, in: OstProbleme 6 (1954), Nr. 10, S. 378-381 (Erstveröffentlichung: The Twentieth Century (London), Januar 1954). 
schen Geheimdienstapparat auszuschalten; vorerst allerdings auf »unblutige« Weise. Im Kontext der Ausschaltung Berijas wurden im Zuge der Auflösung des früheren NKWD-Apparates zum Beispiel auch der ehemalige Minister für Staatssicherheit Ignatjew sowie der stellvertretende Minister und Leiter der Untersuchungsabteilung Rjumin beschuldigt, in der »Ärzte-Affäre« willkürlich Personen verhaftet und Geständnisse erpresst zu haben, sodass beide verhaftet und ihrer Posten enthoben wurden.

Auf der anderen Seite führte die Säuberung der früheren Sicherheitsorgane nach dem Tode Stalins durch die »kollektive Führung« aber auch dazu, dass der totalitäre Druck auf die sowjetische Gesellschaft nachließ. Der einzelne Bürger oder ganze Bevölkerungsgruppen mussten nicht mehr wie in den vergangen Zeiten unter Stalin in ständiger Angst leben, in die Mühle der Verfolgungsapparate zu geraten. Das Nachlassen der terroristischen Praxis führte sogar zu einer »Liberalisierung« der tatsächlichen Verhältnisse in den sowjetischen Konzentrationslagern. Durch den Tod Stalins und nicht zuletzt nachdem Tausende deutscher Kriegsgefangene und zahlreiche andere Häftlinge aus den sowjetischen Lagern entlassen wurden, machte sich bei den übrigen Gefangenen Hoffnung breit. So entstand ein neues Klima unter den Häftlingen in den Konzentrationslagern, wodurch der Boden vorbereitet wurde, auf dem die Bereitschaft wuchs, gegen die (Arbeits-)Bedingungen in den Lagern zu rebellieren, von dem ohne Zweifel der Aufstand im Sommer 1953 im Lager Workuta der größte war. ${ }^{520}$

Gleichwohl bedeutete dies kein endgültiges Ende des Terrors. Genauso zeigte sich, dass die neue sowjetische Führung mit Malenkow und Chruschtschow an der Spitze bereit war, den Kampf gegen den ehemaligen stalinistischen Geheimdienstapparat und gegen den damaligen Leiter Berija nicht ausschließlich mit »unblutigen « Methoden zu führen. Im Dezember des Jahres 1953 hatten sie keine Skrupel, Berija und leitende Funktionäre der sowjetischen Sicherheitsorgane als »Verräter« und »Agenten des Imperialismus« in einem Prozess anzuklagen und sie zum Tode zu verurteilen, die unweigerlich Erinnerungen an die Zeiten Stalins hervorriefen ließ. Diese durchgeführte Maßnahme richtete sich speziell gegen führende Funktionäre der »alten« Sicherheitsorgane und fand vor dem Hintergrund der anvisierten Umstruktuierung der ehemaligen stalinistischen Geheimpolizei statt, die mit der Reorganisation und Säuberung der Geheimdienstapparate in den Satellitenländern korrespondierte. Das wesentliche Ziel bestand einerseits in einer Trennung von Innenministerium (MWD) und Sicherheitsministerium (MGB) und andererseits in einer Unterordnung der staatlichen Sicherheitsorgane unter die Partei. In diesem Zusammenhang gingen die »blutigen « Säuberungen auch im Jahre 1954 weiter und es kam zu Verhaftungen, Prozessen und Erschießungen. So fand beispielsweise im Dezember 1954 vor dem obersten Militärgericht in Leningrad ein Prozess gegen Wiktor S. Abakumow und weitere führende Exponenten des ehemaligen NKWD-Apparates statt. Sie wurden beschuldigt, in Zusammenarbeit mit Berija die "Leningrader Affäre« fabriziert zu haben und seinerzeit die verhafteten Leningrader Parteifunktionäre misshandelt und erpresst zu haben. Sämtliche Angeklagten wurden zum Tode verurteilt und erschossen (im Juli

520 Vgl. hierzu speziell Joseph Scholmer, Der Streik in Workuta, in: Der Monat 6 (1954), H. 66, S. 563-585, sowie auch Otto Maar, ওutschinor. Erlebnisse eines deutschen Wissenschaftlers in Sowjetrußland, in: Der Monat 7 (1955), H. 77, S. 409-424. 
1955 wurde dann der zwei Jahre zuvor verhaftete führende stellvertretende Minister für Staatssicherheit und Leiter der Untersuchungsabteilung, Rjumin, hingerichtet). Sämtliche »blutigen" Säuberungsmaßnahmen und Schläge gegen führende Mitarbeiter des früheren stalinschen »Super-Apparats « fanden vor dem Hintergrund der Umstrukturierung der staatlichen Sicherheitsorgane statt. Aus diesem Grund wurde der frühere NKWD-Apparat durch das im März 1954 ins Leben gerufene Komitee für Staatssicherheit (KGB) unter der Führung von Iwan A. Serow ersetzt, mit der nicht zuletzt die rein formelle Trennung der Staatssicherheitsorgane vom Innenministerium deutlich gemacht werden sollte.

Wie wurden im Monat die Umstrukturierung der sowjetischen Sicherheitsorgane und angesprochenen Säuberungsaktionen unter der Leitung der neuen Machthaber interpretiert? Wo wurden zentrale Unterschiede im Hinblick auf die Rolle der Geheimpolizei unter Stalin bzw. der »kollektiven Führung« gesehen? Wie wurde das Nachlassen des Terrors im Allgemeinen und gegenüber der sowjetischen Bevölkerung im Speziellen in den ersten beiden Jahren nach dem Tod Stalins bewertet? Inwiefern wurde ein Zusammenhang mit den parallel verlaufenden Prozessen in den Satellitenländern gesehen? Last but not least: Wie wurde in diesem Zusammenhang das »neue« sowjetische Herrschaftssystem aufgrund der zurückliegenden Entwicklung charakterisiert?

In seinem Beitrag Die Zähmung der Geheimpolizei setzte sich Löwenthal im Februar des Jahres 1955 mit diesem Fragenkomplex auseinander. ${ }^{521}$ Nachdem im Folgenden die hier interessierenden entscheidenden Passagen von Löwenthal referiert werden und besonders der Autor ausführlich persönlich »zu Wort« kommt, erfolgt anschließend ein Kommentar.

Angesichts der innenpolitischen Veränderungen und den seit Stalins Tod ins Leben gerufenen Reformen - beispielsweise in der Agrarpolitik - sowie den damit verbunden Widersprüchen für die Konsolidierung der Parteidiktatur in der Sowjetunion $^{522}$ stand für Löwenthal fest:

Auf einem Cebiet aber hat das vergangene Jahr eine ganz eindeutige Machtverschiebung gebracht - da, wo sich »neuer Kurs« und Festigung der Parteiherrschaft nicht widersprechen, sondern gleichbedeutend sind: in der demonstrativen Unterwerfung der Ceheimpolizei, sowohl Rußlands wie der Satellitenstaaten, unter die Kontrolle der »kollektiven Führung«der Partei.

Es ist heute nachträglich klar, daß sowohl die Liquidierung des »Ärztekomplotts«durch Beria wie der spätere Sturz Berias selbst Etappen dieses Prozesses waren. Im Jahre 1954 hat sich dieser Prozeß mit der Schaffung einer der Regierung unterstellten »Kommission für Staatssicherheit« (KCB) im März, mit der Exekution Rjumins, des »Erfinders« des Ärztekomplotts, im Juli, mit einer Serie von Desertionen früher verantwortlicher Funktionäre des sowjetischen Ceheimapparats, mit der beginnenden stillen Revision der Säuberungen der letzten Jahre Stalins durch die Freilassung der Brüder Field und einer Reihe sekundärer überlebender Opfer in den Satellitenstaaten, und schließlich mit der Hinrichtung des früheren Staatssicherheitsministers Abakumow und seiner Mitarbeiter fortgesetzt. ${ }^{523}$

521 Richard Löwenthal, Die Zähmung der Geheimpolizei, in: Der Monat 7 (1955), H. 77, S. 467-471.

522 Siehe hierzu im Einzelnen ebd., S. 467.

523 Ebd. 
Im Anschluss daran thematisierte Löwenthal ausführlich, wie Stalin den staatlichen Geheimdienst nach dem Tod Lenins in den 1920er-Jahren zu einem genuinen Instrument bei der Konstituierung seiner Alleinherrschaft machte, indem er nämlich den GPU-Apparat auch und vor allem dazu nutzte, ihn zu einem Instrument in den innerparteilichen Kämpfen zu machen. Danach machte sich Stalin Löwenthal zufolge daran, »sich für die Kontrolle der ungeheuren bürokratischen Pyramide seines Reiches mehr auf seinen ausgedehnten privaten Geheimapparat - das persönliche Sekretariat mit Vertretern in allen Zweigen der Verwaltung - und auf die Geheimpolizei als auf die Parteiführung [zu verlassen], die er weniger und weniger konsultierte«. Daraus folgte für Löwenthal, dass zwar die bis dahin übliche Praxis, Streitfragen durch Säuberungen zu entscheiden, geblieben war, die Partei aber, die der »rationalen Diskussion beraubt« war, abstarb. »Die Polizei blieb unter dem Diktator - aber über der Partei.« ${ }^{524}$

Nach dieser entscheidenden Erkenntnis, dass in der Herrschaftsära Stalins die Geheimpolizei über der Partei stand, oder anders gesagt, dass der Apparat der sowjetischen Geheimpolizei dem Zugriff der KPdSU entzogen war, ging Löwenthal auf den unmittelbar vor dem Tod Stalins grassierenden innenpolitischen Terror ein, der seiner Auffassung nach die Vorbereitung für eine erneute »blutige Säuberung« unter den führenden Funktionären der Partei war. Er interpretierte die Zerschlagung des "stalinischen Super-Apparats«, also die Reorganisation speziell der sowjetischen staatlichen Sicherheitsorgane unmittelbar nach Stalins Tod sowie den anschließenden Schlag gegen Berija seitens der »kollektiven Führung« folgendermaßen (die mit Blick auf bestimmte Aspekte insbesondere aufgrund neuer Informationen und Quellen als eine Präzisierung zu früheren Erklärungsversuchen von Löwenthal aufzufassen waren): »Die >Aufdeckung< des angeblichen Ärztekomplotts im Januar 1953《, so Löwenthal,

gab selbst den höchsten Parteiführern Grund, vor den Konsequenzen zu zittern. Der Tod Stalins kam so den Erben überaus gelegen, und sie beeilten sich, den unmittelbaren Apparat seiner Alleinherrschaft - das persönliche Sekretariat - zu zerschlagen, das »Komplott« als Fälschung zu entlarven, und das Prinzip der »kollektiven Führung« zu proklamieren - dem Wesen nach ein Entschluß, Meinungsverschiedenheiten im engeren Kreis der Partei- und Staatsführung sachlich und ohne Appell an die Polizeigewalt auszutragen. Doch die Beseitigung der Klammer brachte die Gefahr mit sich, daß der Chef des Terrorapparates - des jetzt wieder mit dem Innenministerium (MWD) vereinten Sicherheitsministeriums (MCB) - seine Machtmittel für seine eigenen Ziele einsetzte. Ob die Enthüllungen übergelaufener MCB-Funktionäre [...] zutreffen oder nicht, die Existenz eines selbständigen Apparates mit dieser Tradition der »Säuberungen« war eine tödliche Gefahr für Partei und Parteiführung zugleich, und Berias Bemühungen, die Schlüsselpositionen mit ihm persönlich ergebenen Männern zu besetzen, unterstrichen diese Gefahr noch. Sein Sturz und die Hinrichtung seiner ganzen Gruppe enthüllten ihren vollen Sinn, als der Apparat der Geheimpolizei im März dieses Jahres vom Innenministerium wieder getrennt und einer Kommission für Staatssicherheit unterstellt wurde, die der Sowjetregierung als Ganzem verantwortlich und deren Vor- 
sitzender Iwan Alexandrowitsch Sjerow, weder im engeren Kabinett noch im Parteipräsidium vertreten ist. $^{525}$

Auch die Schläge gegen führende Mitarbeiter der sowjetischen Geheimpolizei aus dem Jahre 1954 - wie zum Beispiel gegen Rjumin und Abakumow - zielten für Löwenthal in diese Richtung, nämlich gewissermaßen die letzten Reste der politischen Macht des früheren Geheimdienstapparates abzubauen und den Prozess, ihn dem KGB zu unterstellen und mithin unter die Kontrolle der Partei zu bringen, zum Abschluss zu bringen. Ebenso in den osteuropäischen Satellitenländern wie zum Beispiel in Ungarn und Polen, so Löwenthal:

Parallel dazu ist auch der frühere Chef der ungarischen Ceheimpolizei, Gabor Peter, zu lebenslänglicher Haft verurteilt worden, und am Ende des Jahres wurde das polnische Ministerium für Staatssicherheit nach russischem Muster aufgespalten und reorganisiert, die eigentliche Geheimpolizei einer Kommission unterstellt und der bisherige Minister, Stanislaw Radkiewicz auf einen Wirtschaftsposten abgeschoben.

Jede dieser Maßnahmen war von öffentlichen Ceständnissen begleitet, daß die Polizeigewalt in der Vergangenheit zu gesetzwidrigen Übergriffen gegen treue Staatsbürger und Kommunisten mißbraucht worden war, und von der Rehabilitierung überlebender Opfer früherer Säuberungen.

»Wenn auch die Triebkräfte dieser Veränderung«, schrieb Löwenthal in diesem Zusammenhang weiter, »in der Spitze des Regimes zu suchen sind, so greifen ihre Wirkungen doch tief in das Leben des Sowjetreiches ein.«Denn, so die Auffassung des Autors:

[K]aum eine andere Maßnahme der Erben Stalins hat das gesamte gesellschaftliche Klima so weitgehend verändert. Natürlich ist die Sowjetunion nicht plötzlich ein Rechtsstaat geworden, und Verurteilungen und Hinrichtungen von »Spionen« finden nach wie vor statt - doch es scheint sich dabei um wirkliche Cegner des Regimes, nicht um die Austragung innerparteilicher Kämpfe mit polizeilichen Mitteln zu handeln. Durch die Trennung von Geheimpolizei vom Innenministerium, das die Herrschaft über die riesigen Zwangsarbeitslager und Verbannungsgebiete ausübt, ist auch ihre wirtschaftliche Macht gebrochen worden; und die Anwendung »halbfreiwilliger Methoden der Rekrutierung für die neuen Siedlungsgebiete in Sibirien und Kasakistan [...] macht den Eindruck, daß eine neue Vergrößerung des Reichs der Sträflingsarbeit um weitere Millionen bewußt vermieden worden ist. Die Einstellung der Kanalbauten und ähnlicher Projekte zur »Transformation der Natur«, die völlig auf Zwangsarbeit angewiesen waren, wirkt in der gleichen Richtung. ${ }^{526}$

Die nachlassende Bedeutung der Geheimpolizei, d. h. eines Herrschaftsapparats, der in der Ära Stalins die ganze sowjetische Gesellschaft mit willkürlichem (Massen-)Terror überzog und in deren Fänge selbst Mitglieder und Exponenten der staatlichen Partei geraten konnten, zeigte sich nach dem Dafürhalten von Löwenthal im tagtäglichen 
sowjetischen Alltag, oder anders gesagt, in der politischen Praxis. Denn die "neue« Geheimpolizei konnte nicht mehr wie in der Vergangenheit frei schalten und walten, sodass potenziell jeder einzelne Bürger und jedes Parteimitglied Opfer der terroristischen Praxis werden konnte, sondern ihr operativer Spielraum war unter der »kollektiven Führung« im Rahmen der sowjetischen »Rechtsvorschriften« reglementiert und unterstand der Kontrolle der Partei. »Propagandistisch wird diese Abwertung der Geheimpolizei«, so Löwenthal,

vor allem dazu genutzt, den Parteimitgliedern und den Funktionären in Wirtschaft und Verwaltung ein erhöhtes Gefühl der persönlichen Sicherheit und auf dieser Grundlage eine erhöhte Bereitschaft zur Übernahme von Verantwortung zu geben. Wenn ein offiziöser Literat wie Korneitschuk in seinem neuesten Drama von den »Ausgeburten« spricht, die »unter dem Vorwand der Wachsamkeit« so furchtbares Leid verursachten, und die Willkürherrschaft der Polizei gegen loyale Staatsbürger ganz offen diskutiert, so soll der Zuhörer fühlen, daß er nicht mehr vor dem morgendlichen Klopfen an der Tür zu zittern braucht, weil diese Schrecken der Vergangenheit angehören. Der Funktionär einer Partei von zynischen Karrieristen, bei denen längst die Angst an die Stelle des Claubens getreten ist, soll wieder Vertrauen fassen; der Bürokrat, der sich längst angewöhnt hat, keine Entscheidung ohne schriftliche Deckung durch den Vorgesetzten zu treffen, soll wieder den Mut finden, den eigenen Kopf zu gebrauchen und Verantwortung zu übernehmen, ohne Furcht, daß ihm jemand einen Strick daraus drehen wird. Hier verquickt sich die Kampagne für Rechtssicherheit mit einer anderen wichtigen Reform - den Bemühungen des Regimes um den Abbau des lähmenden Überzentralismus in Wirtschaft und Verwaltung durch Förderung der lokalen Initiative und Reduzierung des bürokratischen Wasserkopfes in Moskau. ${ }^{527}$

In seinen Ausführungen in dem Beitrag Die Zähmung der Geheimpolizei brachte Löwenthal genau zum Ausdruck, worin die eigentliche politische Bedeutung der Zerschlagung des früheren, unter der direkten Führung Stalins stehenden sowjetischen Apparates der Geheimpolizei durch die neue »kollektive Führung« bestand: Das zentrale Ziel bestand tatsächlich darin, die "neue« Geheimpolizei wieder unter die Kontrolle der Partei zu bringen, um zu verhindern, dass wie in der unmittelbaren Vergangenheit, also der Ära Stalins, die Geheimpolizei zu einem direkten Instrument bei der Konstituierung eines Herrschaftssystems werden könnte, das unter der Führung einer einzigen Person steht. Löwenthal stellte vor diesem Hintergrund im Unterschied $\mathrm{zu}$ seinen früheren Veröffentlichungen zu Recht expressis verbis fest, warum Berija in erster Linie von der neuen »kollektiven Führung« ausgeschaltet und Opfer einer »blutigen« Säuberung wurde: Es sollte verhindert werden, dass nach dem Tod Stalins ein neuerliches genuin totalitäres Herrschaftsregime entstehen könnte, das unter der Führung eines einzigen Mannes steht und der sich im Kontext der Alleinherrschaft in erster Linie auf die Geheimpolizei stützen kann. Insofern lag er ganz auf der Linie der zeitgenössischen Sowjetforschung. ${ }^{528}$ Da Berija in seiner neuen Funktion als Innenminister auch Chef der politischen Polizei war und folglich auch Zugriff auf den »alten«

527 Ebd., S. 469.

528 Vgl. hierzu: Chruschtschew und die »kollektive Führung«, in: Ost-Probleme 7 (1955), Nr. 21, S. $822-826$ (hier S. 825). 
NKWD-Apparat hatte, wurde er von seinen Rivalen aus der »kollektiven Führung « ausgeschaltet, um zu verhindern, dass nicht zuletzt auch wieder »blutige« Parteisäuberungen in Gang kommen könnten mit der »tödlichen Gefahr« für die Parteiführung um Malenkow und Chruschtschow.

Vor dem Hintergrund der zentralen Erkenntnisse seines Beitrages Die Zähmung der Geheimpolizei folgte im Hinblick auf die Analyse des kommunistischen Einparteienregimes unter der Führung der »kollektiven Führung « nach dem Tod Stalins, dass der Kommunismusexperte zweifelsohne einen Abbau des willkürlichen (Massen-)Terrors stalinscher Couleur und mithin einen Bruch mit dem Stalinismus konstatierte, aber trotzdem noch von einem totalitären Herrschaftscharakter des Nachstalinismus ausging. Zumindest könnten die Ausführungen so interpretiert werden, denn:

1. Durch die Zerschlagung des früheren Geheimdienstapparates sowie des genuinen Privatsekretariats Stalins wurde das stalinistische Führungsprinzip angegriffen, sodass eine zentrale Voraussetzung des stalinistischen Herrschaftssystems geändert wurde.

2. Korrespondierend mit der Zerschlagung der allmächtigen Geheimpolizei, kam es zu einem Nachlassen des Terrors. Vor allem kam es zu einem Ende des für den Stalinismus charakteristischen Phänomens des permanenten (Massen-)Terrors, der sich in erster Linie dadurch auszeichnete, dass die herrschende Partei unter der Führung von Stalin im Namen des zu erreichenden Zieles, also der Realisierung der kommunistischen Utopie in der Sowjetunion, immer neue »innere (Klassen-)Feinde « fand, ${ }^{529}$ da sich ebendieses Ziel nicht im Kontext eines »naturwüchsigen« Prozesses in der nachrevolutioären sowjetischen Gesellschaft einstellte. Der Terror besaß einen willkürlichen Charakter und richtete sich auch und vor allem gegen die eigene Bevölkerung. Damit war bereits ein entscheidender qualitativer Unterschied des Regimes in den ersten beiden Jahren nach Stalins Tod zum Stalinismus genannt. In der »Nach-StalinÄra« mussten, wie Löwenthal richtig feststellte, die sowjetischen Bürger nicht mehr mit der tagtäglichen konkreten Angst leben, Opfer von willkürlichen Verhaftungsoperationen des Geheimdienstes zu werden, da zumindest in Ansätzen eine »Rechtssicherheit« herrschte.

3. Zudem zeigte sich die nachlassende Bedeutung des Terrors auch darin, dass tatsächlich das Phänomen der Parteisäuberung, zumal der »blutigen«, im Vergleich zum Stalinismus nicht mehr - bis auf wenige Ausnahmen - eine zentrale Bedeutung hatte. In der neuen sowjetischen Führung bestand im Grunde genommen eine Übereinstimmung, die Geheimpolizei nicht mehr als ein Instrument in der innerparteilichen Auseinandersetzung einzusetzen, um tatsächliche oder »eingebildete« Gegner auszuschalten. Fortan galt der Primat der Partei, d.h. in diesem Zusammenhang, die Herrschaft der Partei über die Geheimpolizei, und über interne Streitfragen sollte eine "freie« Diskussion zumindest in der unmittelbaren Führungsspitze möglich sein. Insofern sollten Streitfragen und innerparteiliche Machtkämpfe »unblutig« ausgetragen werden.

4. Auch die Bedeutung der sowjetischen Konzentrationslager war im Vergleich zum Stalinismus am schwinden. Nicht nur, dass zumindest ein kleiner Teil der Insassen entlassen wurden, sondern allein die Tatsache, dass im Gegensatz zur Vergan-

529 Vgl. hierzu G. f. Hudson, Chruschtschews Arbeitsstil, in: Ost-Probleme 8 (1956), Nr. 4, S. 110-114, hier S. 111; Erstveröffentlichung: The Twentieth Century, Dezember 1955. 
genheit das Millionen Menschen umfassende »Heer« von Zwangsarbeitern nicht mehr anstieg, stellte bereits eine historische Zäsur dar. Im Gegensatz zur zurückliegenden üblichen terroristischen Praxis »begnügte« sich das nachstalinistische Regime in diesem Zusammenhang mit der »halbfreiwilligen « Methode, um Arbeiter zu finden. ${ }^{530}$

5. Ein Ende des totalitären »Alptraums« machte sich Löwenthal zufolge nicht nur im Alltag der sowjetischen Bürger bemerkbar, sondern auch in den offensichtlichen Bestrebungen der neuen sowjetischen Machthaber, den »normalen« Parteimitgliedern und den Funktionären in der Wirtschaft und der Verwaltung ein größeres Gefühl der »persönlichen Sicherheit« zu vermitteln, damit ihr politischer Alltag weniger von Angst und Furcht besetzt ist.

6. Auch wenn Löwenthal nicht ausdrücklich auf die seit dem Sommer 1953 einsetzende Liberalisierung des kulturellen Lebens in der Sowjetunion einging, die zweifelsohne auch eine Abkehr vom Stalinismus bedeutete, weil damit der totalitären ideologisch-politischen Überwachung und Lenkung ebendieser gesellschaftlichen Sphäre ein Ende bereitet wurde und die Ilja Ehrenburg im Titel seiner Novelle als Das Tauwetter bezeichnete, kam trotzdem in seinem Beitrag klar zum Ausdruck, dass sogar in der zeitgenössischen »offiziösen« sowjetischen Literatur eine »offene« Kritik am stalinistischen Terror formuliert wurde.

Zudem kam in den Ausführungen Löwenthals sehr genau zum Ausdruck, aus welchen Gründen und warum sich die »blutigen« Säuberungen gegen Berija, Rjumin oder auch Abakumow seitens der neuen »kollektiven Führung« im Kontext der Reorganisation der staatlichen Sicherorgane durchgeführt wurden und warum der KGB im Jahre 1954 gegründet wurde. ${ }^{531}$ Ebenso kam richtig zum Ausdruck, warum dieser institutionelle und personelle Entstalinisierungsprozess parallel auch in den Satellitenstaaten wie zum Beispiel in Ungarn und Polen - in Gang kam.

Ebenso kam in den Ausführungen Löwenthals Anfang des Jahres 1955 zumindest implizit zum Ausdruck, dass die neue sowjetische Führung, d. h. in diesem Zusammenhang vor allem Malenkow und Chruschtschow, nicht »über Nacht« nach dem Tod Stalins »bessere« Menschen geworden waren, die aus - man könnte sagen - politischer und ideologischer Überzeugung dem Terror im Großen und Ganzen ein Ende bereitet hatten. Nicht aus grundsätzlichen Gründen, d.h. in erster Linie aus individuellen Skrupeln physische Gewalt einzusetzen, verzichteten sie auf die Methode des (systematischen) Terrors. Dass die neuen sowjetischen Machthaber das Ende des Stalinismus einleiteten und den politischen Boden für den Nachstalinismus bereiteten, war vor allem den genuinen Bedingungen des »Neuen Kurs« in der Sowjetunion geschuldet, sprich: der Überzeugung, einen im Vergleich zu Stalin grundsätzlich anderen wirtschaftlichen Kurs einzuschlagen, der auch eine »Reform « der Partei und der Gesellschaft notwendig machte. Insofern lag der Autor richtig mit seiner Feststellung, dass die »Kampagne für Rechtssicherheit« sich mit anderen wichtigen Reformen des Regimes, speziell in »Wirtschaft und Verwaltung«, wie er schrieb, »verquickte«.

530 Zu der Veränderung im sowjetischen System der Konzentrationslager vgl. grundsätzlich Richard K. Carlton (Hg.), Forced Labor in the »People’s Democracies«, New York 1955 sowie B. Jakowlew, Konzentrazionnye lageri SSSR. Hg. v. Institut zur Erforschung der Geschichte und Kultur der UdSSR, München 1955.

531 Vgl. hierzu auch: Vom Apparat zermalmt, in: Ost-Probleme 7 (1955), Nr. 2, S. 75 f. 
Worauf Löwenthal in diesem Zusammenhang nicht ausdrücklich hinwies, war die Tatsache, dass die führenden Exponenten des »neuen« Regimes in der Vergangenheit den Terror von Stalin direkt und indirekt mitgetragen hatten und im Grunde genommen eine politische, ideologische und psychologische Affinität zum ehemaligen Kremlchef hatten. Zum Beispiel war Chruschtschow in den 1930er-Jahren als "Stalinist « und erster Parteisekretär erst in Moskau und dann vor allem in der Ukraine während der Säuberung direkt in den Terror verstrickt.

Dass die »Zähmung der Geheimpolizei« durch die »kollektive Führung« in der Sowjetunion sich bereits konkret im Jahre 1954 auf die Reorganisation der Geheimdienste in den Satellitenstaaten auswirkte, darauf ging Löwenthal, wie gezeigt, in seinem Beitrag bereits ein, als er exemplarisch in Kürze die Veränderung in Ungarn und Polen beschrieb. Wie allerdings der »neue Kurs« die grundsätzlichen Beziehungen Moskaus zu den Satellitenstaaten beeinflusste, war Anfang des Jahres 1955 in den Augen von Löwenthal keineswegs eindeutig. ${ }^{532}$

Gleichzeitig zeigte sich aber um die Jahreswende 1954/55, dass das Regime nicht bereit war, die seit dem Sommer 1953 einsetzende Liberalisierung des kulturellen Lebens im Allgemeinen und in der Literatur im Besonderen in dieser Form beizubehalten. Nachdem die beiden viel gelesenen Romane Die Jahreszeiten von Vera Panowa und Tauwetter von Ilja Ehrenburg - die beide trotz erheblicher Bedenken seitens großer Teile der Partei sowie einiger Exponenten der sowjetischen Führung um Malenkow und Chruschtschow veröffentlicht wurden - unverhohlene Kritik nicht nur am stalinistischen System schlechthin formulierten, sondern auch eine »Rebellion« gegen den seit dem Ersten Kongress der sowjetischen Schriftsteller im Jahre 1934 verordneten "sozialistischen Realismus" darstellte, schlug die Partei zurück. Unter anderem mit dem Zweiten Unionskongress der Sowjetschriftsteller im Dezember 1954 machte die Partei den Intellektuellen und Schriftstellern klar, dass dem »Protest « und der »Kritik« an den sowjetischen Zuständen Grenzen gesetzt waren und dass fortan wieder Parteitreue in der Literatur erwartet wird. ${ }^{533}$

Diese regressive Entwicklung in der sowjetischen Kulturpolitik fand vor dem Hintergrund des sich immer mehr zuspitzenden Machtkampfes zwischen Malenkow und Chruschtschow statt. Zu Beginn des Jahres 1955 wurde immer mehr sichtbar, dass sich das Regime nach dem Tod Stalins in einer Art Übergangsphase befand und dass die »Todfeindschaft« (Borkenau) zwischen den beiden führenden Repräsentanten in der zurückliegenden Phase nur »auf Eis« gelegt war. Auf der Sitzung des Obersten Sowjets vom 8. Februar 1955 gab Ministerpräsident Malenkow seinen Rücktritt bekannt. Als Grund nannte er, sich selbst beschuldigend, die unbefriedigende Lage der Landwirtschaft und das Zurückbleiben in der Schwerindustrie. Der »neue Kurs« hatte die Sowjetunion wirtschaftlich überfordert, da, so hatte es den Anschein, Rüstung und Lebensstandart nicht gleichzeitig gehoben werden konnten. Die militärischen Überlegungen, die Ausgaben für die Rüstung nicht zu vernachlässigen, hätte unter Umständen noch berücksichtig werden können. Allerdings wurde vonseiten »Rotchinas« an Moskau der Wunsch geäußert, den Ausbau der dortigen Schwerindustrie zu unterstützen. Das war der entscheidende Punkt, der tatsächlich das Konzept von Malenkow

532 Siehe hierzu im Einzelnen Richard Löwenthal, Die Zähmung der Geheimpolizei, in: Der Monat 7 (1955), H. 77, S. $469 \mathrm{ff}$.

533 Vgl. im Einzelnen Alfred Burmeister, Der zweite Frost, in: Der Monat 7 (1955), H. 77, S. 472-474. 
zerstört hatte, als Mao Tse-tung im Oktober 1954 Chruschtschow und dem Verteidigungsminister Bulganin ebendiese Wünsche in Peking vortrug. Auf dem Moskauer ZK-Plenum Ende Januar 1955 formulierte in erster Linie Chruschtschow starke Kritik gegenüber Malenkow, dem er die Vernachlässigung der Schwerindustrie zugunsten der Konsumindustrie sowie eine allzu »defensive« Politik gegenüber den westlichen Staaten zum Vorwurf machte. ${ }^{534}$ Anders gesprochen: Die Kritik zielte in erster Linie auf die von Malenkow seit dem Tod Stalins favorisierte »Entspannungspolitik« der Sowjetunion gegenüber den westlichen Ländern. ${ }^{535}$

Zum Nachfolger Malenkows wurde Bulganin ernannt. Das Amt des Verteidigungsministers übernahm Schukow, den Stalin nach Kriegsende ins Abseits gestellt hatte. Indes: Der eigentliche politische Sieger des Regierungswechsels war Chruschtschow, der jetzt, nachdem seine beiden eigentlichen Rivalen Berija und Malenkow um die Nachfolge Stalins ausgeschaltet waren, als Erster Sekretär des ZK der KPdSU über die Regierungsgeschäfte des sowjetischen Staates sowie über die weitere Entwicklung der Entstalinisierung entscheidend bestimmten konnte. Dabei war der »tödliche« Gegensatz zwischen Chruschtschow und Malenkow nach 1953 zunächst für Außenstehende kaum sichtbar geworden. Allerdings richtete bereits der Prozess gegen den ehemaligen Sicherheitsminister Abakumow im Dezember 1954 durchaus den Schweinwerfer auf die Rivalität. Darauf ging Borkenau im Monat ein - vor dem Hintergrund einer vehementen Kritik an Kennans illusionären Vorstellungen über das Wesen des Sowjetregimes und die internationale Politik im Kontext des Kalten Krieges. ${ }^{536}$ Noch kurz vor dem Rücktritt Malenkows thematisierte er nicht nur weitere Aspekte für die Hintergründe des Prozesses, sondern sah insbesondere den innerparteilichen Konkurrenzkampf und Richtungsstreit sozusagen voraus. Angesichts einer veränderten »Atmosphäre« in Moskau, so Borkenau:

erfolgte die Erschießung des früheren Polizeiministers Abakumow, gerade wegen der »Leningrader Affäre«, d. h. wegen der Verhaftung und Folterung jener Shdanowisten, die heute laut amtlicher Meldung - soweit noch am Leben - wieder völlig rehabilitiert sind. Dort stößt jetzt wieder lebhaft die extreme Richtung vor. Es ist ein interessantes Symptom, daß gerade jener Chef der politischen Hauptverwaltung der Armee, der 1949 mit Wossnessensky verschwand, im Dezember 1954 eine militärische Auszeichnung erhielt. Ich bin nicht der Meinung, daß die von Chruschtschow geführte Richtung unbedingt siegen wird. Doch ist es keine Frage der Meinung, sondern einfach eine Tatsache, daß Chruschtschow die alten Shdanowisten um sich zu sammeln versucht und daß er bei jeder Gelegenheit öffentlich seinen unveränderten tödlichen Haß gegen den »Kapitalismus betont. $^{537}$

534 Vgl. Richard Löwenthal, Das russische Dilemma, in: Der Monat 7 (1955), H. 78, S. 561-565.

535 Vgl. ders., Ist der Friede ausgebrochen?, in: Der Monat 7 (1954), H. 75, S. 196.

536 Vgl. hierzu Ceorgef. Kennan, Die Sonne und der Nordwind. Gedanken zur Lösung der Ost-WestSpannung, in: Der Monat 7 (1955), H. 76, S. 291-300.

537 Franz Borkenau, Der Wanderer knöpft den Mantel fester!, in: Der Monat 7 (1955), H. 78, S. 565-569, hier S. 566. 
Diese Zeilen von Borkenau erreichten die Zeitschrift Der Monat bereits »drei Wochen vor dem Rücktritt Malenkows «. ${ }^{538}$ In der selben Ausgabe, dem Märzheft des Jahres 1955, wurden zwei längere Zitate von Borkenau unter der Überschrift Kreml-Astrolo$g i e^{539}$ veröffentlicht, in der er seine Fähigkeit unter Beweis stellte, den »Zweikampf« zwischen Chruschtschow und Malenkow sowie den Rücktritt von Malenkow am 8. Februar 1955 vorauszusagen. Am 2. Juli 1954 schrieb er damals in der Weltwoche:

Chruschtschow greift also nach der Krone, nach Stalins Nachfolge, und das nicht ohne Erfolg. Zäh und systematisch vertreibt er die Anhänger Malenkows aus dem Parteiapparat [... Er] versucht, das Armeekommando in seine persönliche Klientel zu verwandeln. Der Ausgang des inneren Parteikampfes wird ohne Zweifel von Erfolg oder Mißerfolg dieses Versuches mitbestimmt werden [...]. Der Staat steht vor einer Entscheidung: entweder muß er den Bauern umfassende Konzessionen machen, was Malenkow offenbar für das Richtige hält - oder man muß Stalins alten Plan verwirklichen, die bäuerlichen Kolchosen in Staatsgüter verwandeln und den Bauern den letzten Rest ihrer Selbständigkeit nehmen. Letzteres erstrebt Chruschtschow auf dem Umweg über eine Massengründung von Staatsgütern am Rande der landwirtschaftlich genutzten Cebiete [...].

Und am 4. Februar 1955 schrieb Borkenau wieder in der Weltwoche:

Der Sturz Mikojans ist der erste große Sieg Chruschtschows auf Malenkows eigenstem Gebiet [...]. Wenige Stunden vor der Mitteilung vom Falle Mikojans brachte die »Prawda« einen Leitartikel, der von einem gewissen Schepilow in seiner Eigenschaft als Mitglied des Zentralkomitees gezeichnet war. Dieser Schepilow ist kein anderer als der Chef der »Prawda« selbst; doch sein Name hat bisher niemals unter einem Artikel gestanden. Mit dieser seiner persönlichen Unterschrift bekundete Schepilow, in einer im Sowjetjargon unmißverständlichen Sprache, daß er die »Prawda«, die nichts als ein anonymes Sprachrohr des Politbüros sein sollte, jetzt für seinen [d. h. seiner Richtung] Kampf gegen eine andere Richtung innerhalb der Partei einsetzt. Es ist diese Unterschrift, die, deutlicher als viele Worte, den Ausbruch des offenen Kampfes im Kreml verkündet $\left[. . .{ }^{540}\right.$

Die sowjetische Innenpolitik stand unter dem neuen Parteiführer fortan im Zeichen des Primats der Schwerindustrie und der Erhöhung des Rüstungsbudgets. Auch in der Außenpolitik hatte sich Chruschtschow zum Ziel gesetzt, neue Akzente zu setzen. Angesichts des in der Sowjetunion nach dem Tod Stalins in Gang gekommenen Entstalinisierungsprozesses und unter anderem vor dem Hintergrund des Aufstandes vom 17. Juni 1953 in Ostdeutschland wurden in den osteuropäischen Satellitenstaaten neue Hoffnungen wach, für sich selbst größere Bewegungsfreiheit, wenn nicht gar die vollständige Selbstständigkeit gegenüber Moskau zu erlangen. In diesem Zusam-

538 So die redaktionelle Mitteilung ebd., S. 566.

539 Zur sogenannten Methode der »Kreml-Astrologie« vgl. grundsätzlich Franz Borkenau, Was ist Kreml-Astrologie?, in: Der Monat 7 (1955), H. 79, S. 32-39.

540 Zit. n. Der Monat 7 (1955), H. 78, S. 563. Zum »Zweikampf« zwischen Chruschtschow und Malenkow und den politischen Implikationen für das sowjetische Regime nach dem Rücktritt Malenkows und der Installierung Bulganins zum Ministerpräsidenten vgl. auch grundsätzlich: Chruschtschew und die »kollektive Führung«, in: Ost-Probleme 7 (1955), Nr. 21, S. 822-826. 
menhang sollte insbesondere der anvisierte »neue Kurs« gegenüber Jugoslawien eine wesentliche Wendung in der sowjetischen Außenpolitik anzeigen. Im Mai 1955 trafen Chruschtschow und Bulganin in Belgrad ein, um die diplomatischen und politischideologischen Beziehungen mit dem ehemaligen »faschistischen Verräter« Tito neu zu ordnen bzw. zu »normalisieren«. In einer Erklärung gab Chruschtschow dem »imperialistischen Agenten« (Löwenthal) Berija die Schuld am Konflikt, der seit 1948 eine antijugoslawische Kampagne ins Leben gerufen haben sollte. Gleichwohl erreichte Chruschtschow sein primäres Ziel nicht. Denn er hatte den Besuch bei Tito mit der Absicht gemacht, das ehemalige Dogma Stalins von der alleinigen Führerschaft der Sowjetunion im kommunistischen Lager durch die Demonstration zu ersetzen, dass "gute« Kommunisten unabhängige Verbündete Moskaus sein können, um Jugoslawien auf einer neuen Grundlage, will heißen: auf "gleichberechtigter« Basis, für den sowjetischen »Block« in Osteuropa zurückzugewinnen. Da Tito auf das Angebot der »Normalisierung« der Beziehungen der beiden Staaten eher ablehnend reagierte, endete die Reise für den neuen Kremlchef enttäuschend, zumal er sich hiervon auch aus innerparteilichen Gründen einen »Prestigeerfolg« erhofft hatte. Letzten Endes musste Chruschtschow einlenken und Jugoslawien weiterhin das Recht einräumen, seinen eigenen nationalen Weg zum Sozialismus zu gehen, sodass bereits Mitte des Jahres 1955 die Gefahr bestand, dass die Macht der Sowjetunion - nicht zuletzt in Folge des von Moskau geforderten »neuen Kurses« sowie des Entstalinisierungsprozesses insgesamt - in einzelnen osteuropäischen Satellitenstaaten sukzessive unterminiert werden könnte. Mit anderen Worten: Es mehrten sich zu diesem Zeitpunkt die Anzeichen - zumal im Falle des »Nagy-Regimes« in Ungarn - für eine Lockerung der Beziehungen der Sowjetunion und den unter ihrer »Kontrolle« stehenden osteuropäischen Satellitenstaaten. ${ }^{541}$

Das offensichtliche Einlenken Moskaus gegenüber Jugoslawien im Sommer 1955 verstärkte die Hoffnungen in den Ländern des sozialistischen Lagers, dass man in $\mathrm{Zu}$ kunft wieder eigene Meinungen vertreten könne und einheimische nationale Gruppen der Kommunisten sich gegenüber den absolut moskauhörigen Führungseliten durchsetzen könnten. Ebendiese Hoffnungen verstärkten sich vor allem nach der scharfen Abrechnung mit Stalin auf dem XX. Parteitag der KPdSU im Februar 1956. Indes: Der Parteitag sollte zunächst in erster Linie für den seit dem Tod Stalins in Gang gesetzten »Entstalinisierungskurs« in der Sowjetunion selbst eine einschneidende Bedeutung haben.

\subsection{Der XX. Parteitag der KPdSU und die Folgen oder: das "Jenseits des Stalinismus"}

Der XX. Parteitag der KPdSU fand vom 14. Februar bis zum 25. Februar 1956 im Moskauer Kreml statt. Sein wichtigstes Ergebnis war bekanntlich einerseits die radikale Zertrümmerung des stalinschen Personenkults, mit dem gleichzeitig die Alleinherrschaft Stalins kritisiert wurde, und andererseits die auf einer geschlossenen Sondersitzung vorgetragene Geheimrede Chruschtschows. Hier informierte Chruschtschow

541 Zum Besuch Chruschtschows in Belgrad und zu den Folgen insgesamt vgl. Richard Löwenthal, Brief aus Belgrad: Acht Tage, die ein Reich erschütterten, in: Der Monat 7 (1955), H. 82, S. 319-328. 